\title{
Advanced and futuristic approaches for breast cancer diagnosis
}

\author{
Jayanti Mishra ${ }^{*}$ (D, Bhumika Kumar, Monika Targhotra and P. K. Sahoo
}

\begin{abstract}
Background: Breast cancer is the most frequent cancer and one of the most common causes of death in women, impacting almost 2 million women each year. Tenacity or perseverance of breast cancer in women is very high these days with an extensive increasing rate of 3 to $5 \%$ every year. Along with hurdles faced during treatment of breast tumor, one of the crucial causes of delay in treatment is invasive and poor diagnostic techniques for breast cancer hence the early diagnosis of breast tumors will help us to improve its management and treatment in the initial stage.

Main body: Present review aims to explore diagnostic techniques for breast cancer that are currently being used, recent advancements that aids in prior detection and evaluation and are extensively focused on techniques that are going to be future of breast cancer detection with better efficiency and lesser pain to patients so that it helps to a physician to prevent delay in treatment of cancer. Here, we have discussed mammography and its advanced forms that are the need of current era, techniques involving radiation such as radionuclide methods, the potential of nanotechnology by using nanoparticle in breast cancer, and how the new inventions such as breath biopsy, and $X$-ray diffraction of hair can simply use as a prominent method in breast cancer early and easy detection tool.

Conclusion: It is observed significantly that advancement in detection techniques is helping in early diagnosis of breast cancer; however, we have to also focus on techniques that will improve the future of cancer diagnosis in like optical imaging and HER2 testing.
\end{abstract}

Keywords: Breast cancer, Diagnostics, Techniques, Advancement, Future

\section{Background}

Breast cancer is the most predominant form of cancer in females worldwide. It has been observed that its persistence rate is also very high, ranges from $20-30 \%$ [1] that shows an extensive increase of $3.1 \%$ cases from 641,000 to $1,643,000$ cases in 1980 . The persistence rate during stage 0 and 1 is $98 \%$ whereas in stage 3 it is $65 \%$. Incidence of breast cancer rates is found to be maximal in the 55-65 year age group [2] (as shown in Table 1), and its survival rates are very less as soon as patients reach stage 3 of the disease (as shown in Table 2). It is found that one in every six females is prone to breast cancer these days [5] as stated in Fig. 1 [6]. In most cases,

\footnotetext{
* Correspondence: jayanti.dipsar@gmail.com

Department of Pharmaceutics, Delhi Institute of Pharmaceutical Sciences and Research, Sector-3, MB Road, Pushp Vihar, Delhi 110017, India
}

patients do not get treatment at the right time due to tumor progression hence early diagnosis is the most critical requirement that helps in the early treatment of this disease [5]. Majorly, mammography is the uttermost favored technique used for cancer detection; however, due to the severe disadvantage in younger women, numerous other techniques have been evolved [7]. Recent expansion in the biology of breast tissues has led to the easier measurement of different biological procedures like an evaluation of gene expression, molecular biology, and cellular biochemistry using digital methods, tomosynthesis, CAD, and other methods like radionuclide method [8] that has led to the detection of breast tumors devoid of using in vivo method and directly using radiation contact [9]. 
Table 1 Incidences of breast cancer with increasing age [3]

\begin{tabular}{ll}
\hline Age (years) & Breast cancer cases (\%) \\
\hline $20-35$ & 2 \\
$35-45$ & 10 \\
$45-55$ & 22.5 \\
$55-65$ & 24.5 \\
$65-75$ & 20 \\
$75-85$ & 15.5 \\
Above 85 & 5.5 \\
\hline
\end{tabular}

\section{Mammography and its advancements}

Currently, it is the most accepted method used for tumor detection in the breast using a low dose of $\mathrm{X}$ rays. It is mainly recommended as a routine examination for women above 40 years of age [10]. Based on the display of images, it is of two types: film mammography that gives an image on films, and digital mammography that gives images on the computer system [11]. Film mammography has been used for so long but film processing is slow and we cannot change image contrast later that presently limits its uses [12]. Different advanced approaches (as shown in Fig. 2) such as digital mammography, contrast-enhanced mammography, tomosynthesis, and CAD are developed and used recently which are described below.

\section{Digital mammography}

Digital mammography gives an improved quality of images in a shorter duration of time as compared to film mammography [14]. In this, all the steps, such as accession, processing, and display of images separated individually. It gives a broader range of resolution and densities in dense breasts with minimal noise during image accession [15]. It does not require additional images or exposure of patients to unnecessary radiation and uncomfortable tests for the processing of breast images [16]. DM has given a platform to the CAD software that is used to produce data in digital formats with improved sensitivity in the dense breasts in pre- or postmenopausal females or females under the age of 50 years [17]. Management and manipulation of images are

Table 2 Breast cancer survival rates at different stages [4]

\begin{tabular}{ll}
\hline Stage & Breast cancer survival rates \\
\hline 0 & $100 \%$ \\
1 & $100 \%$ \\
2 & $93 \%$ \\
3 & $2 \%$ \\
4 & $22 \%$ \\
\hline
\end{tabular}

controlled electronically with better efficiency and reliability. Dense breast tissues which appear white in film mammograms; DM provides better contrast image with clear differences from other tissues [18]. Image fusion and image transmission from one physician to another are fast and easy. Spurgeon et al. have shown the efficacy of digital mammography is more in tumor or lesions diagnosis [19]. This suggests that DM is continuously putting back to conventional mammography techniques in soft copy evaluations, diagnostic, and screening settings in breast cancer detection [20].

\section{Contrast-enhanced digital mammography}

Contrast enhancement digital mammography is an advancement of digital mammography that includes two techniques, temporal subtractions technique, and bifoldenergy techniques [21]. The temporal subtraction technique provides images before and after the exposure of iodine-based contrast agents. Dual-energy techniques provide twain of images with variable energies after exposure of contrast agents [22]. Recently available methods in contrast-enhanced mammography are confined to the diagnosis of one breast at a time whereas MRI (magnetic resonance imaging) of breast detects the presence of tumors in both breasts at a time and helps in the diagnosis of contralateral tumors [23]. Hence, a combination of contrast agent's exposure using magnetic resonance imaging and ultrasound provides the advantage of breast imaging with greater sensitivity and precision [24].

\section{Tomosynthesis}

To overcome the problem of digital mammography that sometimes gives superimposable tumor structures or may abstruse lesions in the breast with dense tissues during diagnosis, tomosynthesis has come as a useful advancement for breast cancer evaluation [25] with more sensitivity and specificity than conventional mammography technique. This term tomosynthesis was first termed by Grant et al. [26]. Tomosynthesis involves the use of tungsten or rhodium anodes and filters with panel detectors along with different multi-slit scanning systems [27]. This is based on the parallax method that shows the structure's closer to the detector will move for shorter distances between images than structures that are far away from the detector [28]. Tomosynthesis also provides better differentiation between benign and malignant tumors. It removes noise and separates planes of images through the breast for quality images but due to this, tomosynthesis also detect calcified tissues as similar to tumor tissues with clarity up to $92 \%$ that is one of the reasons of its limited use [29]. 


\section{Facts of Breast cancer in women}

Early detection of breast cancer improves survival rates upto $98 \%$

$I$ in 6 women are prone to this

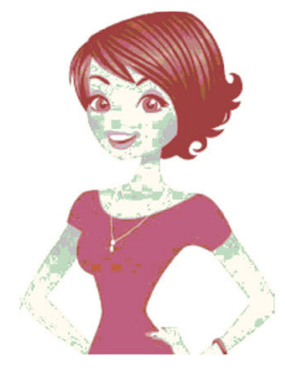

Mammography can detect tumors at early stage when it is most treatable
More than $80 \%$ patients of breast cancer are with no family history

I $^{\text {nd }}$ Leading cause of death in female

Fig. 1 Facts about breast cancer [6]

\section{CAD mammography}

Computer-aided detection (CAD) applies computer technology with mammography or MRI techniques to detect structural changes masses etc. that helps in early diagnosis of breast cancer [30]. It provides a bridge between conventional techniques and artificial technology. It applies successfully to both film and digital mammography. CAD helps in the easy detection of micro calcified tissues than masses of tumors [31]. It is still under improvement and its major drawback is its overemphasized sensitivity to changes in breast tissues that result in unnecessary biopsies [32]. However, significant benefits have been obtained from this in the past several years so it may be considered as a significantly useful technique in the future [33].

\section{Recent advanced techniques for early diagnosis of breast cancer \\ 2D FDTD analysis}

2D FDTD stands for 2 dimensional finite difference time domain technique that uses electromagnetic rays for computational analysis of tumors [34]. It includes analysis of the physical properties of breast tissues such as the interaction of biomolecules of breast tissues based on dielectric constant comparable to tissue water content with microwave radiations and location of tumors beneath the skin. It has shown experimentally that the dielectric constant and conductance of malignant cells is greater than normal cells which are measurable by microwaves technology [34]. 2D FDTD aims to increase tumor detection in breast and eradication of tissue heterogeneity by using pulsed confocal method ad time gating. 2D FDTD is effective to detect tumors with $2 \mathrm{~mm}$ or smaller in width in the presence of heterogeneity of normal breast tissues [35]. 2D FDTD aims to increase tumor detection in breast and eradication of tissue heterogeneity by using pulsed confocal method ad time gating [36]. It is comparably safer and comfortable than conventional mammography as it requires examination of only one side of the breast and no exposure to ionizing radiations that have been facilitating its use for screening and monitoring of individual persons with breast cancer.

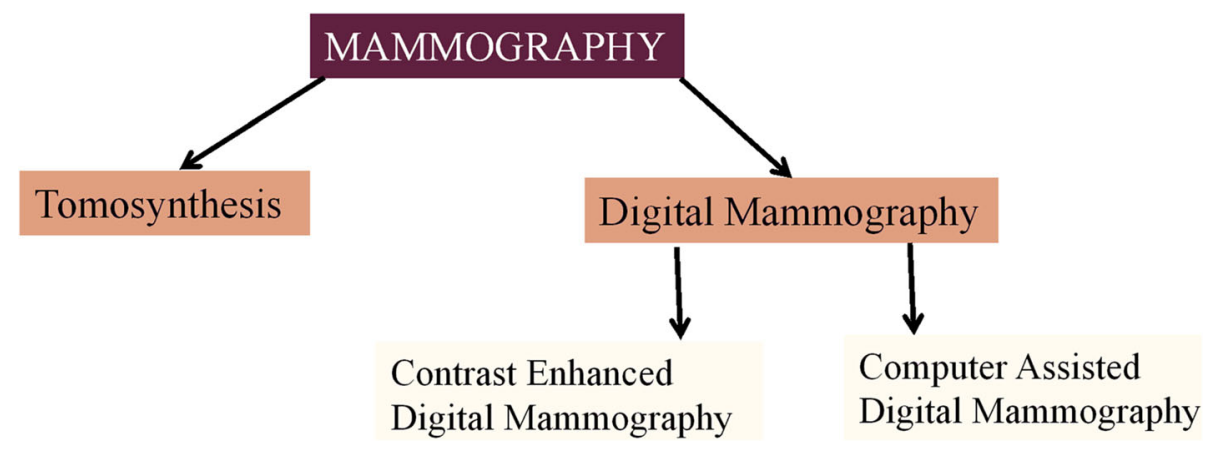

Fig. 2 Mammography and its advancements [13] 


\section{Radionuclide methods}

Radionuclide methods provide greater specificity and contrast between tumor and normal breast cancer tissue [37]. It also helps in the assessment of the stage of cancer and improvement in therapy responses. Methods using these techniques include positron emission tomography (PET), scintimammography, positron emission mammography (PEM), and breast specific gamma imaging (BSGI) [38]. Scintimammography was used earlier using MIBI radiopharmaceutical agents which is cationic in nature, along with gamma cameras [39]. Lieberman et al. used scintimammography for breast cancer detection and found sensitivity up to $85 \%$ and specificity about $87 \%$ [40]. It has poor detection sensitivity to breast lesions less than $1 \mathrm{~cm}$ in size and those are non-palpable in nature.

Positron emission tomography used for imaging anatomy and understanding molecular biology differences between normal and tumor tissues [41] uses mainly FDG, i.e., 6F-fluoro-2-deoxy-D-glucose and ${ }^{18} \mathrm{~F}$-fluoride as tracers in breast imaging [42]. Accumulation of FDG reduces with a decrease in tumor viability in the area concerned. PET has better spatial resolution and greater accuracy for image quantification. The use of PET is still limited in use because of low sensitivity for smaller and non-palpable lesions and poor ability in primary cancer detection [43]. Breast staging gamma imaging (BSGI) consists of gamma cameras for breast cancer imaging. It is also used for the detection of dense breasts and lesions of $1 \mathrm{~cm}$ or less. It has limited use in clinical practice because of high dose exposure of radionuclide to patients hence only used I clinical trial investigation of breast cancer [44]. Positron emission mammography or PEM uses a lower dose of radionuclide and having a high spatial resolution as compared to PET. PEM helps to detect lesions in the breast even less than $2 \mathrm{~mm}$ in size. Along with MRI, it provides more specificity to the tumor and avoids unnecessary biopsy for cancer diagnosis [45]. Currently, different variants of PEM system containing different types of detectors are used like for compressed breast diagnosis: stationary flat detectorbased PEM scanners and for uncompressed breast diagnosis: rotating detector-based PEM scanners or stationary full or partial detector ring-based PEM scanner is used [46]. Hence, new advanced systems improve the use of radionuclide imaging in breast cancer diagnosis.

\section{Nanoparticles}

These days, biocompatible and active nanoparticles are used as contrast agents to increase specificity in breast cancer imaging [47]. It avoids unnecessary biopsies and provides radioactive signals with increased sensitivity [48]. Nanoparticles are considered beneficial diagnostic agents due to increased blood retention time, large surface area, or different ligands interaction that may use in the diagnosis of breast cancer. Nanoparticles with iron oxides produce strong MRI contrast of breast tissues having variable surface characteristics [49]. Nanoparticles using Bismuth metal are used as contrast agents in computed tomography resulted in increased pharmacokinetics and absorption properties with improved safety than iodinating agents [50]. It is still under development, and in the future, it can play a significant role in the future in oncology.

\section{Futuristic approaches to be used for breast cancer detection}

\section{Breathe biopsy}

Exhaled breath consists of more than thousands of volatile components that represents a rich source of biological components in the human body. Breath biopsy (BB) helps to access this information by analyzing breath samples to stratify biomarkers for early disease diagnosis, detect response to the therapy, etc. BB is a completely non-invasive technique that maximizes patient comfort. $\mathrm{BB}$ can act as an important means for the people suffering from the beginning time of malignancy and show asymptomatic or imprecise side effects [51]. Patients can allude from essential consideration into specific consideration. Authorities can, in this way, execute further developed techniques such as biopsies of tissues to examine their illness.

A spearheading breath analyzer was intended to gather emanated breath with volatile organic compounds [52] that can be possibly related to provocative disorders, irresistible ailments, malignant growth, and possibly particular sorts of malignant cancer. Gas chromatography, heat desorption, and field asymmetric ion mobility spectrometry (FAIMS) are passed down for sample detection by cutting edge recognition microchip innovation for built-up mass spectroscopy (MS) for a biomarker for volatile organic compound revelation. Such complex accumulation and investigation methods build the medical breath biopsy R stage [53]. Early and less costly disease location is the main real zone for medical's breath biopsy (BB) stage is taking advantage of and is troth to profit. ReCIVAR sampler is non-invasive, torment, and unpaid, having a moderately low cost contrasted and various disease location strategies take $1 \mathrm{~min}$ to gather breathed out breath with signified volatile organic compound is a reproducible course for breath accumulation and can be utilized anyplace not simply the emergency clinic. The cartridge catches do not require exceptional dealing with after transportation. Owlstone's FAIMS innovation gives quick, delicate, and specific VOC examination. This relatively small-in-size breathalyzer is seeking to achieve a monumental mission, saving 100,000 lives and US $\$ 1.5$ billion in healthcare costs [54]. 


\section{Mammary ductoscopy}

Mammary ductoscopy refers to a technique, which allows introduction of a micro endoscope into breast milk ducts facilitating inspection of the ductal epithelial lining and recovery of cells for analysis by lavage and biopsy. Mammary ductoscopy is a developing strategy enabling a forthright viewable approach to the ductal arrangement of bosom using the nipple hole cannula and investigation [55]. Initial studies of MD evaluated women with pathologic spontaneous nipple discharge (PND), while more recent reports are also using MD to assess women without PND for the presence of breast cancer [56]. It offers the upsides of exact localization of pathophysiology and intraoperative direction particularly for sores profound inside the ductal framework. The mammary pipe framework was effectively cannulated for the viability studies [57]. Furthermore, tumors detection could be categorized as polypoid, superficial, and combined type. The polypoid type was most normal in instances of intraductal papilloma, and the superficial sort was most basic in instances of carcinoma [58]. Mammary ductoscopy is embedded through a cannula into the hole of intracystic tumors. Apparently, malignant tumors appeared to be as irregular and rough in shape and cause bleeding also whereas benign tumor does not cause any bleeding and have smooth surfaces. Additional sample evaluation using image or molecular analysis may improve the sensitivity and specificity of MD in breast cancer detection [59].

\section{X-ray diffraction of hair}

$\mathrm{X}$-ray diffraction of hair is a non-invasive method of diagnosing breast cancer which is reported with the use of synchrotron small-angle X-ray scattering of hair fibers. A correlation has been observed in women with breast cancer showing a change in X-ray diffraction in their hair, with a new ring superimposed on the normal diffraction pattern of $\alpha$-keratin [60]. The use of X-beam diffraction on hairs of people with tumors in the breast has shown that an "extra segment" could hypothetically tie to the $\alpha$-keratin strands shaping in the middle of the road fibers or to other auxiliary components, for example, the lipid bi-layers [61]. It is likewise possible that expulsion of any unessential material from the fiber would return its X-beam diffraction example to resemble that of a typical hair. This idea was tried during the present as a component of an inquiry for the hidden physiology [62]. X-ray beam diffraction investigation needs a solitary hair fiber to be tenderly expelled from by the compartment utilizing sharp forceps and stacking it onto an authentic sample holder for holding 10 singular hair filaments [63]. Such sample holders utilize small expansion springs to get a handle on fiber to find the filament in the fitting direction for the X-rays. Spring was used to unwind the clip to fiber. The hairs were set neighboring the finding pins then the spring was delicately discharged. A lot of consideration was taken with the stacking procedure that was not contorted during stacking or that it was not harmed by extending. When stacked, the hairs were inspected under a dismembering stereo magnifying lens. All things considered, the hair was inspected at a separation of $10 \mathrm{~mm}$ from the trim ends, likening to about a month of hair development. This technique has been observed sensitive for both early and metastatic breast cancer diagnosis [62].

\section{HER2 testing}

Human epidermal growth factor receptor 2 (HER2) is an oncogene, with huge homology to human epidermal growth factor receptor $1 /$ human epidermal growth factor receptor3 (HER1/HER3) and human epidermal growth factor receptor 4 (HER4), which drives expansion, movement, and attack in breast cancer disease [64]. The HER2 quality is intensified in around 15-20\% of breast malignancies [65] and quality intensification is firmly connected to over appearance of the HER2 protein [66]. From a clinical point of view, tumors with typical HER2 levels are alluded to as either "HER2-ordinary" or "HER2-negative" (lacking HER2 overexpression/intensification), while tumors with quality enhancement/overexpression are alluded to as "HER2-positive" [67]. The HER2-focused on operators' trastuzumab, lapatinib, pertuzumab, and trastuzumab emtansine [68] have altogether amended diagnostic results in patients with HER2-positive breast malignant growth in the metastatic \& ancillary settings [69]. Various such testing methods are currently accessible-that is already affirmed by the USFDA [70]. These tests are categorized into two parts: the IHC test means immunohistochemical tests and the FISH test means fluorescent in situ hybridization tests. These tests are completely mechanized, medium-term measures that physicians can decipher by using a splendid field magnifying instrument [71]. Present FISH HER2 tests include numerous manual methods, everyone represents the danger of changeability, which improves the probability of an off base test outcome [72]. For instance, fluorophores are corrupted by presentation to light, so all arrangements having these chemicals must be dealt with in diminished light.

\section{Magnetic resonance elastography}

Magnetic resonance elastography is also known as MRE, which is a quickly rising and constructive system considering the location and portrayal of a wide scope of ailment forms [73]. Magnetic resonance elastography (MRE) is a novel non-invasive technique to measure the spatial stiffness of soft tissues. Contrast-enhanced breast magnetic resonance imaging (MRI) is the most sensitive 
imaging modality for breast cancer detection and is indicated for screening women at high risk for breast cancer, evaluating extent of disease in patients with a known breast carcinoma, and monitoring therapy. By investigating the biological and mechanical properties or both tissues that differ broadly in physiologic and pathologic states MRE restores data that is past the capacities of traditional imaging procedures that depend only on etymological changes for recognizing illness [74]. In a time of expanding reception of multi-methodology procedures for assessing complex sickness forms [75], MRE might be joined to a magnetic resonance imaging assessment to give a quick, dependable, and complete imaging evaluation at a solitary patient arrangement [76]. Another use of MRE that is being examined with extraordinary intrigue is for the appraisal of breast malignant growth. It is generally rigid than kind-hearted sores and ordinary bosom tissue. Standard percussion is a suggested piece of screening technique for bosom malignancy and aides in the identification of such hard tissues [77]. While breast MRE is highly sensitive for cancer detection, it has been historically limited in its use due to a lower specificity because of an overlap in appearances between benign and malignant lesions [78].

\section{Optical imaging}

Optical breast imaging is a novel imaging technique that uses near-infrared (NIR) light to assess the optical properties of tissues, and is expected to play an important role in breast cancer detection. Optical imaging is an assistant gadget to conventional imaging methods [79], in light of the fact that the data picked up with the optical sign is uniquely not quite the same as that of the clinical imaging data [80]. Because of various logical prospects and innovative advancement in histological optics, optical imaging currently seems possible in a different stratum of explicitness and goals better than previous improvements [81]. Deeper tissue penetration allows optical imaging to be implemented as an imaging technology for breast cancer detection, diagnosis, and/or prognosis. Optical imaging provides a functional imaging approach with decent spatial resolution and contrast. Optical imaging also requires less imaging time compared to MRI, and is also less expensive. At the point where fluorescent tests are energized by infrared radiation, breast imaging utilizing a fluorescent differentiation operator that may expand sore complexity and also conceivably recognize variations in bosom tissue histology [82]. These tests can either ties explicitly to specific targets related to disease or can collect nonspecifically at the tumor area, for the most part by extravasations through defective vessels. In the future optical imaging agents could, potentially, be used as "theranostics," combining the process of diagnosis and therapy [83].

\section{Conclusion}

One of the major issues in the treatment of breast cancer is the lack of timely detection of tumor which is due to poor diagnostic techniques that are being used currently that delay detection of this cancer as these methods are time consuming and cumbersome in nature. Incidence of breast cancer rates is found to be maximal in the 55-65 year age group and its survival rates are very less as soon as patients reach stage 3 of the disease. To combat these problems, modern techniques and recent advancements in diagnosis are a boon to mankind as they can provide early detection in lesser time and are also non-invasive in nature; thus, breast cancer can be treated at its earliest stage when compared to conventional methods. Therefore, it is necessary to use new techniques and concentrate on development in the diagnosis of the disease so that treatment of the disease can be made easier and in less possible time.

\section{Abbreviations}

CAD: Computer-aided detection; DM: Digital mammography; MRI: Magnetic resonance imaging; 3D: 3 Dimensional; 2D FDTD: 2 Dimensional finite difference time domain; PET: Positron emission tomography; BSGI: Breast staging gamma imaging; PEM: Positron emission mammography; BB: Breath biopsy; HER1: Human epidermal growth factor receptor 1; HER2: Human epidermal growth factor receptor 2; HER3: Human epidermal growth factor receptor 3; HER4: Human epidermal growth factor receptor 4

\section{Acknowledgements \\ I would like to thank the Department of Pharmaceutics, DIPSAR (Delhi) for providing me the necessary sources.}

\section{Authors' contributions}

All the authors contributed equally for the completion of the present manuscript under supervision of PKS. JM proposed Conception and design of the article, MT completed the drafting of the proposed article, analysis and revision of the manuscript done by BK, and PKS performed the final editing of the given manuscript. All the authors have read and approved the manuscript before submission.

\section{Funding \\ NA}

Availability of data and materials

All data and materials are available upon request.

Ethics approval and consent to participate

NA

Consent for publication

NA

Competing interests

The authors declare that they have no competing interests.

Received: 6 May 2020 Accepted: 15 September 2020

Published online: 27 October 2020

References

1. Na KY, Kim KS, Lee JE, Kim HJ, Yang JH, Ahn SH, Moon BI, Kim RM, Ko SM, Jung YS (2011) The 70-gene prognostic signature for Korean breast cancer patients. J Breast Canc 14:33-38 
2. Costa VRA, Biller G, Uemura G, Ruiz CA, Curado MP (2017) Breast cancer screening in developing countries. Clinics 72:244-253

3. Yamamoto D, Shoji T, Kawanishi H, Nakagawa H, Hajima H, Gondo H, Tanaka K (2001) A utility of ductography and fiberoptic ductoscopy for patients with nipple discharge. Breast Cancer Res Treat 70:103-108

4. Wang B, yanfang Y, Zhansheng J, Zhao J, Mao Y, Liu J, Zhang J (2019) Clinicopathological characteristics, diagnosis, and prognosis of pregnancyassociated breast cancer. Thorac Cancer 10(5): 1060-1068.

5. Akram M, lqbal M, Daniyal M, Khan AU (2017) Awareness and current knowledge of breast cancer. Biol Res 50:33-33

6. King TA, Morrow M (2015) Surgical issues in patients with breast cancer receiving neoadjuvant chemotherapy. Nat Rev Clin Oncol12:335-343.

7. Singh V, Saunders C, Wylie L, Bourke A (2008) New diagnostic techniques for breast cancer detection. Futur oncol 4:501-513

8. Mambou SJ, Maresova P, Krejcar O, Selamat A, Kuca K (2018) Breast cancer detection using infrared thermal imaging and a deep learning model. Sensors 18:2799

9. Jalalian A, Mashohor S, Mahmud R, Karasfi B, Saripan MIB, Ramli ARB (2017) Foundation and methodologies in computer-aided diagnosis systems for breast cancer detection. In EXCLI J, pp 113-137.

10. Pauwels EKJ, Foray N, Bourguignon MH (2016) Breast cancer induced by Xray mammography screening? A review based on recent understanding of low-dose radiobiology. Med Princ Pract 25:101-109

11. Kim HS, Han BK, Choo KS, Jeon YH, Kim JH, Choe YH (2005) Screen-film mammography and soft-copy full-field digital mammography: comparison in the patients with microcalcifications. Korean J Radiol 6:214-220

12. Ganesan K, Acharya UR, Chua CK, Min LC, Abraham KT, Ng KH (2013) Computer-aided breast cancer detection using mammograms: a review. Biomed Eng 6:77-98

13. Dieckman F, freyer M, Dieckman S, Fallenberg Eva M, Fischer T, Ulrich B, Pollinger A (2009) Evaluation of contrast-enhanced digital mammography. Eur J Radiol 78(1):112-121.

14. Faridah Y (2008) Digital versus screen film mammography: a clinical comparison. Biomed Imaging Interv J 4:e31-e31

15. Nees AV (2008) Digital mammography: are there advantages in screening for breast cancer? Academ Radiol 15:401-407

16. Wang J, Kato F, Yamashita H, Baba M, Cui Y, Li R, Oyama-Manabe N, Shirato H (2017) Automatic estimation of volumetric breast density using artificial neural network-based calibration of full-field digital mammography: feasibility on Japanese women with and without breast cancer. J Digit Imaging 30:215-227

17. Choi BH, Lee EH, Jun JK, Kim KW, Park YM, Kim HW, Kim YM, Shin DR, Lim HS, Park JS, Kim HJ, Alliance for Breast Cancer Screening in K (2019) Effect of different types of mammography equipment on screening outcomes: a report by the alliance for breast cancer screening in Korea. Korean J Radiol 20: $1638-1645$

18. Dromain C, Balleyguier C, Adler G, Garbay JR, Delaloge S (2009) Contrastenhanced digital mammography. Eur J Radiol 69:34-42

19. Singla D, Chaturvedi AK, Aggarwal A, Rao SA, Hazarika D, Mahawar V (2018) Comparing the diagnostic efficacy of full field digital mammography with digital breast tomosynthesis using BIRADS score in a tertiary cancer care hospital. Indian J Radiol Imaging 28:115-122

20. Ekpo EU, Alakhras M, Brennan P (2018) Errors in mammography cannot be solved through technology alone. Asian Pac J Cancer Prev 19:291-301

21. Shtern F (1992) Digital mammography and related technologies: a perspective from the National Cancer Institute. Radiol 183:629-630

22. Diekmann F, Bick U (2007) Tomosynthesis and contrast-enhanced digital mammography: recent advances in digital mammography. Eur Radiol 17: 3086-3092

23. Diekmann F, Diekmann S, Jeunehomme F, Muller S, Hamm B, Bick U (2005) Digital mammography using iodine-based contrast media: initial clinical experience with dynamic contrast medium enhancement. Investigat Radiol 40:397-404

24. Salem DS, Kamal RM, Mansour SM, Salah LA, Wessam R (2013) Breast imaging in the young: the role of magnetic resonance imaging in breast cancer screening, diagnosis and follow-up. J Thorac Dis 1:S9-S18

25. Mall S, Lewis S, Brennan P, Noakes J, Mello-Thoms C (2017) The role of digital breast tomosynthesis in the breast assessment clinic: a review. J Med Radiat Sci 64:203-211

26. Fischer U, Kopka L, Grabbe E (1999) Breast carcinoma: effect of preoperative contrast-enhanced MR imaging on the therapeutic approach. Radiol 213:881-888
27. Grant DG (1972) Tomosynthesis: a three-dimensional radiographic imaging technique. Biomed Eng 19:20-28

28. Patel T, Peppard H, Williams MB (2016) Effects on image quality of a $2 D$ antiscatter grid in X-ray digital breast tomosynthesis: initial experience using the dual modality (X-ray and molecular) breast tomosynthesis scanner. Med Phys 43:1720

29. Diekmann F, Diekmann S, Berzeg S, Bick U, Fischer T, Hamm B (2003) Dose reduction through gridless technique in digital full-field mammography. Rofo 175:769-774

30. Kopans DB (2014) Digital breast tomosynthesis from concept to clinical care. AJR 202:299-308

31. Mabrouk MS, Afify HM, Marzouk SY (2019) Fully automated computer-aided diagnosis system for micro calcifications cancer based on improved mammographic image techniques. Ain Shams Eng J 10:517-527

32. Jalalian A, Mashohor S, Mahmud R, Karasfi B, Saripan MIB, Ramli ARB (2017) Foundation and methodologies in computer-aided diagnosis systems for breast cancer detection. In Excli J 113-137.

33. Tang J, Rangayyan RM, Xu J, El Naqa I, Yang Y (2009) Computer-aided detection and diagnosis of breast cancer with mammography: recent advances. Eng Med Biol Soc 13:236-251

34. Hagness SC, Taflove A, Bridges JE (1998) Two-dimensional FDTD analysis of a pulsed microwave confocal system for breast cancer detection: fixedfocus and antenna-array sensors. Biomed Eng 45:1470-1479

35. Fear E, Stuchly M (2000) Microwave detection of breast cancer. Microwave Theory and Techniques 48:1854-1863

36. Xiao X, Kikkawa T (2008) Influence of the organism interface on the breast cancer detection by UWB. Appl Surf Sci 255

37. Surti S (2013) Radionuclide methods and instrumentation for breast cancer detection and diagnosis. Semin Nucl Med 43:271-280

38. Narayanan D, Berg WA (2018) Dedicated breast gamma camera imaging and breast PET: current status and future directions. PET Clin 13:363-381

39. Khalkhali I, Mena I, Diggles L (1994) Review of imaging techniques for the diagnosis of breast cancer: a new role of prone scintimammography using technetium-99 m sestamibi. Eur J Nucl Med 21:357-362

40. Das BK, Biswal BM, Bhavaraju M (2006) Role of scintimammography in the diagnosis of breast cancer. Malays J Med Sci 13:52-57

41. Shukla AK, Kumar U (2006) Positron emission tomography: an overview. J Med Phys 31:13-21

42. Alauddin MM (2012) Positron emission tomography (PET) imaging with (18)F-based radiotracers. Am J Nucl Med Mol Imaging 2:55-76

43. Specht JM, Mankoff DA (2012) Advances in molecular imaging for breast cancer detection and characterization. Breast Cancer Res 14:206-206

44. lakovou I, Giannoula E, Gkantaifi A, Levva S, Frangos S (2018) Positron emission tomography in breast cancer: $18 \mathrm{~F}-\mathrm{FDG}$ and other radiopharmaceuticals. Eur J Hyb Imaging 2:20

45. Glass SB, Shah ZA (2013) Clinical utility of positron emission mammography. Bayl Univ Med Cent 26:314-319

46. Raylman RR, Majewski S, Smith MF, Proffitt J, Hammond W, Srinivasan A, McKisson J, Popov V, Weisenberger A, Judy CO, Kross B, Ramasubramanian S, Banta LE, Kinahan PE, Champley K (2008) The positron emission mammography/tomography breast imaging and biopsy system (PEM/PET): design, construction and phantom-based measurements. Phy Med bio 53: 637-653

47. Nune SK, Gunda P, Thallapally PK, Lin Y-Y, Forrest ML, Berkland CJ (2009) Nanoparticles for biomedical imaging. Expert Opin Drug Deliv 6:1175-1194

48. Naseri N, Ajorlou E, Asghari F, Pilehvar-Soltanahmadi Y (2018) An update on nanoparticle-based contrast agents in medical imaging. Artificial Cells Nanomed Biotechnol 46:1111-1121

49. Dulińska-Litewka J, Łazarczyk A, Hałubiec P, Szafrański O, Karnas K, Karewicz A (2019) Superparamagnetic iron oxide nanoparticles-current and prospective medical applications. Materials 12:617

50. Cormode DP, Naha PC, Fayad ZA (2014) Nanoparticle contrast agents for computed tomography: a focus on micelles. Contrast Media Mol Imaging 9: 37-52

51. Vander SM, Pinheiro H, Gaude E (2018) Breath biopsy for early detection and precision medicine in cancer. E Cancer Med Sci 12:84

52. Gaude E, Nakhleh MK, Patassini S, Boschmans J, Allsworth M, Boyle B, van der Schee MP (2019) Targeted breath analysis: exogenous volatile organic compounds (EVOC) as metabolic pathway-specific probes. J Breath Res 13: 032001 
53. Abderrahman B (2019) Exhaled breath biopsy: a new cancer detection paradigm. Future oncol 15:1679-1682

54. Broza YY, Vishinkin R, Barash O, Nakhleh MK, Haick H (2018) Synergy between nanomaterials and volatile organic compounds for non-invasive medical evaluation. Chem Soc Rev 47:4781-4859

55. Tang SS, Twelves DJ, Isacke CM, Gui GP (2011) Mammary ductoscopy in the current management of breast disease. Surgical Endoscopy 25:1712-1722

56. Sarica O, Ozturk E, Demirkurek HC, Uluc F (2013) Comparison of ductoscopy, galactography, and imaging modalities for the evaluation of intraductal lesions: a critical review. Breast Care 8:348-354

57. Joseph MK, Islam M, Reineke J, Hildreth M, Woyengo T, Pillatzki A, Baride A, Perumal O (2020) Intraductal drug delivery to the breast: effect of particle size and formulation on breast duct and lymph node retention. Mol Pharmaceutics 17:441-452

58. Al SW, Worku D, Escobar PF, Mokbel K (2006) Breast papillomas: current management with a focus on a new diagnostic and therapeutic modality Int Semin Surg Oncol 3:1

59. Briki F, Busson B, Salicru B, Estève F, Doucet J (1999) Breast-cancer diagnosis using hair. Nature 400:226-226

60. Mistry DAH, Haklani J, French PW (2012) Identification of breast cancerassociated lipids in scalp hair. Breast Cancer 6:113-123

61. Corino GL, French PW, Lee M, Ajaj MM, Haklani J, Mistry DAH, Phan K, Yuile PG (2009) Characterization of a test for invasive breast cancer using $X$-ray diffraction of hair-results of a clinical trial. Breast Cancer (Auckl) 3:83-90

62. Iqbal N, labal N (2014) Human epidermal growth factor receptor 2 (HER2) in cancers: overexpression and therapeutic implications. Mol Bio Int 852748

63. Krishnamurti U, Silverman JF (2014) HER2 in breast cancer: a review and update. Adv Anatomic Pathol 21:100-107

64. Pfitzner BM, Lederer B, Lindner J, Solbach C, Engels K, Rezai M, Dohnal K, Tesch H, Hansmann ML, Salat C, Beer M, Schneeweiss A, Sinn P, Bankfalvi A, Darb-Esfahani S, von Minckwitz G, Sinn BV, Kronenwett R, Weber K, Denkert C et al (2018) Clinical relevance and concordance of HER2 status in local and central testing - an analysis of 1581 HER2-positive breast carcinomas over 12 years. Modern Pathol 31:607-615

65. Gabos Z, Sinha R, Hanson J, Chauhan N, Hugh J, Mackey JR, Abdulkarim B (2006) Prognostic significance of human epidermal growth factor receptor positivity for the development of brain metastasis after newly diagnosed breast cancer. J clinic oncol 24:5658-5663

66. Baez-Vallecillo L, Raghavendra AS, Hess KR, Barcenas CH, Moulder SL, Tripathy D, Valero V, Murthy RK (2019) Lapatinib activity in metastatic human epidermal growth factor receptor 2-positive breast cancers that received prior therapy with trastuzumab, pertuzumab, and/or adotrastuzumab emtansine (T-DM1). Breast cancer res treatment 176:227-234

67. Slamon DJ, Clark GM, Wong SG, Levin WJ, Ullrich A, McGuire WL (1987) Human breast cancer: correlation of relapse and survival with amplification of the HER-2/neu oncogene. Science 235:177-182

68. Gajria D, Chandarlapaty S (2011) HER2-amplified breast cancer: mechanisms of trastuzumab resistance and novel targeted therapies. Expert Rev Anticancer Ther 11:263-275

69. Geyer CE, Forster J, Lindquist D, Chan S, Romieu CG, Pienkowski T, JagielloGruszfeld A, Crown J, Chan A, Kaufman B, Skarlos D, Campone M, Davidson N, Berger M, Oliva C, Rubin SD, Stein S, Cameron D (2006) Lapatinib plus capecitabine for HER2-positive advanced breast cancer. The New Eng J Med 355:2733-2743

70. Petroni S, Caldarola L, Scamarcio R, Giotta F, Latorre A, Mangia A, Simone G (2016) FISH testing of HER2 immunohistochemistry 1+ invasive breast cancer with unfavorable characteristics. Oncol Lett 12:3115-3122

71. Low G, Kruse SA, Lomas DJ (2016) General review of magnetic resonance elastography. World J Radiol 8:59-72

72. Radhakrishna S, Agarwal S, Parikh PM, Kaur K, Panwar S, Sharma S, Dey A, Saxena KK, Chandra M, Sud S (2018) Role of magnetic resonance imaging in breast cancer management. South Asian J Cancer 7:69-71

73. Wang J, Deng Y, Jondal D, Woodrum DM, Shi Y, Yin M, Venkatesh SK (2018) New and emerging applications of magnetic resonance elastography of other abdominal organs. Top Magn Reson Imaging 27:335-352

74. Zhang J, Li Y, Zhao Y, Qiao J (2018) CT and MRI of superficial solid tumors. Quant Imaging Med Surg 8:232-251

75. Vreugdenburg T, Willis C, Mundy L (2013) A systematic review of elastography, electrical impedance scanning, and digital infrared thermography for breast cancer screening and diagnosis. Breast cancer res treatment 137
76. Nazari SS, Mukherjee P (2018) An overview of mammographic density and its association with breast cancer. Breast Cancer 25:259-267

77. Chamberland D, Jiang Y, Wang X (2010) Optical imaging: new tools for arthritis. Integrative Biol 2:496-509

78. Wu M, Shu J (2018) Multimodal molecular imaging: current status and future directions. Contrast Media Mol Imaging 2018:1382183

79. Ruby J, Kumar Ph.D PSJ, Li X, Binford T, Yuan Y, Hu W, Yung Y, Pan M (2019) Intelligent detection of glaucoma using ballistic optical imaging. Adv Eng Informat 40 (2019): 107-127

80. Goel S, Duda DG, Xu L, Munn LL, Boucher Y, Fukumura D, Jain RK (2011) Normalization of the vasculature for treatment of cancer and other diseases. Physiol Rev 91:1071-1121

81. Corino GL, French PW (2008) Diagnosis of breast cancer by X-ray diffraction of hair. Int J Cancer 122:847-856

82. Stanić V, Bettini J, Montoro FE, Stein A, Evans-Lutterodt K (2015) Local structure of human hair spatially resolved by sub-micron X-ray beam. Sci Rep 5:17347

83. Zhu Q, Cronin EB, Currier AA, Vine HS, Huang M, Chen N, Xu C (2005) Benign versus malignant breast masses: optical differentiation with USguided optical imaging reconstruction. Radiol 237:57-66

\section{Publisher's Note}

Springer Nature remains neutral with regard to jurisdictional claims in published maps and institutional affiliations.

\section{Submit your manuscript to a SpringerOpen ${ }^{\circ}$ journal and benefit from:}

- Convenient online submission

- Rigorous peer review

- Open access: articles freely available online

- High visibility within the field

- Retaining the copyright to your article

Submit your next manuscript at $>$ springeropen.com 